\title{
Rancang Bangun Website Sekolah Dengan Menggunakan Framework Bootstrap ( Studi Kasus SMP Negeri 6 Prabumulih )
}

\author{
Andi Christian ${ }^{1}$, Sebri Hesinto ${ }^{2}$, Agustina ${ }^{3}$ \\ Jl. Patra No. 50 Kelurahan Sukaraja Kecamatan Prabumulih Selatan, Sumatera Selatan \\ STMIK Prabumulih \\ andichristian_cdm@yahoo.com¹, Sebrivirgo@yahoo.com²,Agustina.13984268@gmail.com³
}

\begin{abstract}
Abstraksi-- Media informasi yang digunakan di SMP Negeri 6 prabumulih masih manual seperti menggunakan papan pengumuman, spanduk dan berosur sehingga SMP Negeri 6 Prabumulih membutuhkan suatu media informasi yang cepat, tepat, tanpa harus ke sekolah dan dapat di akses secara online oleh masyarakat luas agar mendapatkan informasi yang akurat. Metode yang digunakan dalam penelitian ini ialah dengan metode waterfall dengan menganalisa data yang diperoleh dari sekolahan kemudian membanguna website Sekolah Menengah Pertama Negeri 6 Prabumulih dan Perancangan yang digunakan untuk membuat website sekolah ini yaitu dengan menggunakan program PHP dan untuk desainnya menggunakan Dreamweaver CS6, Bootstrap dan databasenya. Hasil dari penelitian ini adalah agar mempermudah para siswa, guru dan semua komponen yang ada di lingkungan sekolah tersebut untuk mendapatkan informasi dengan cepat dan akurat.
\end{abstract}

Kata Kunci: Sistem Informasi, Website, Sekolah

\section{Pendahuluan}

Website sekolah sekarang ini sedang menjadi tren di dunia pendidikan dan website sekolah mendapatkan perhatian, tanggapan yang sangat bagus dari berbagai pihak baik itu dari tenaga kependidikan, siswa dan juga masyarakat serta keberadaan website sekolah pada saat ini memang sangat penting. Proses penginputan data siswa,data guru dan karyawan disekolah tersebut,akant tetapi sekolah ini belum memiliki website sendiri untuk mempermudah siswa, guru dan karyawan mendapatkan informasi, dengan begitu sulit untuk mengetahui informasi yang ada pada sekolah tersebut.Tujuan diadakan penelitian ini untuk membuat website pada Sekolah Menengah Pertama Negeri 6 Prabumulih. Untuk mempermudah siswa,guru, karyawan dan masyarakat mendapatkan informasi tentang Sekolah Menengah Pertama Negeri 6 Prabumulih dengan cepat. Untuk memperkenalkan Sekolah Menengah Pertama Negeri 6 Prabumulih ke publik melalui website.

\section{TINJAUAN PUSTAKA}

\subsection{Rancang Bangun}

Rancang Bangun adalah program yang menentukan aktifitas pemrosesan informasi yang dibutuhkan untuk penyelesaian tugas-tugas khusus dari pemakai atau pengguna komputer.[8]

1.2 Website
website atau disingkat web, dapat diartikan sekumpulan halaman yang terdiri dari beberapa laman yang berisi informasi dalam bentuk data digital baik berupa text, gambar, video, audio dan animasi lainnya yang disediakan melalui jalur koneksi internet [1]

\subsection{Bootstrap}

Bootstrap adalah paket aplikasi siap pakai untuk membuat front-end sebuah website. Bisa dikatakan, bootstrap adalah template desain web dengan fitur plus. Bootstrap diciptakan untuk mempermudah proses desain web bagi berbagai tingkat pengguna, mulai dari level pemula hingga yang sudah berpengalaman. Cukup bermodalkan pengetahuan dasar mengenai $H T M L$ dan $C S S$, anda pun siap menggunakan bootstrap [5]

\subsection{Pengertian $P H P$}

PHP(Kepanjangan: Hypertext Preprocessor) itu bahasa pemrograman berbasis web. Jadi ,PHP itu adalah bahasa pemrograman yang digunakan untuk membuat aplikasi berbasis web (website, blog atau aplikasi web).[3]

\subsection{MySQL}

MySQL merupakan software RDBMS (server database) yang dapat mengelola database dengan sangat cepat, dapat menampung data dalam jumlah sangat besar, dapat diakses oleh banyak user (multi-user) dan dapat melakukan suatu proses secara sinkron atau berbarengan (multi-threaded).[4]

\section{6 Хampp}

Xampp adalah salah satu paket installer yang berisi Apache yang merupakan web server tempat menyimpan filefile yang diperlukan website, dan Phpmyadmin sebagai aplikasi yang digunakan untuk perancangan database MySQL.[1] 


\subsection{Dreamweaver}

Dreamweaver merupakan suatu perangkat lunak web editor keluaran adobe system yang digunakan untuk membangun dan mendesign suatu website dengan fitur-fitur yang menarik dan kemudahan dalam penggunaannya.[7]

\subsection{Web Server}

Web server adalah sebuah perangkat lunak server yang berfungsi menerima permintaan HTTP atau HTTPS dari klien yang dikenal dengan web browser dan mengirimkan kembali hasilnya dalam bentuk halaman-halaman web yang umumnya berbentuk dokumen HTML. [6]

\section{METODELOGI PENELITIAN}

A. Metode Pengumpulan Data

1. Observasi

Pengumpulan data dengan melakukan pengamatan secara langsung terhadap objek penelitian, terhadap kegiatan yang sedang berlangsung terutama objek yang sedang diteliti.

2. Wawancara

Dalam hal ini penulis melakukan proses interaksi dan komunikasi atau Tanya jawab pada pihak-pihak terkait yang memberikan informasi tentang objek penelitian.

3. Dokumentasi

Teknik dokumentasi digunakan untuk mencari sumber informasi yang ada kaitannya dengan penelitian yang berupa dokumen dan foto.

4. Studi Pustaka

Peneliti mengumpulkan teori-teori buku-buku yang ada perpustakaan sebagai referensi.

\section{B. Metode Pengembangan Sistem}

Metode pengembangan sistem yang digunakan dalam penelitian ini adalah metode model air terjutn atau yang sering disebut dengan istilah waterfall [2]. ada empat tahapan dalam model waterfall yaitu (1). System Engineering (2). Analysis (3). Design (4). Coding. (5). Testing (6). Maintenance Berikut adalah gambaran dari metode

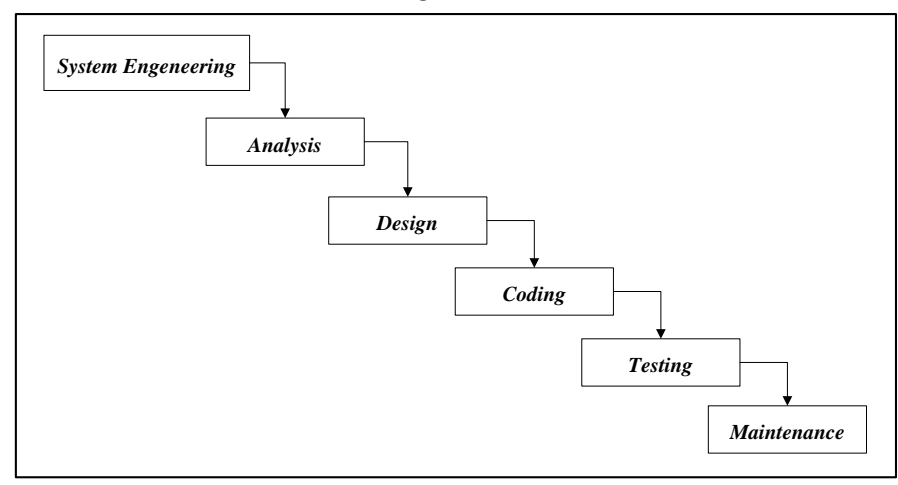

Gambar 3.1 Model Waterfall

1. System Engineering atau rekayasa sistem dan analisa merupakan pembentukan kebutuhan dari semua elemen sistem dan menganalisa kebutuhan keinginan user. Meliputi I/O, walau pengerjaan, ukuran dan jumlah data yang ditangani.
2. Analysis, Analisa kebutuhan sistem dan software adalah proses menentukan arsitektur sistem secara total dan menentukan ukuran data dan jumlah data.

3. Design adalah menentukan dasar-dasar pembentukan dan pemilihan struktur data, struktur program, arsitektur program, pemilihan algoritma, intereksi dengan user.

4. Coding adalah mentrasformasikan desain kedalam barisbaris program, pemilihan bahasa.

5. Testing merupakan pengujian kebenaran program.

6. Maintenance adalah proses perawatan software agar dapat digunakan terus.

C. Alat Bantu Analisis dan Perancangan

1. Diagram Konteks

Diagram konteks adalah diagram yang menggambarkan sumber serta tujuan data yang akan diproses atau dengan kata lain diagram tersebut digunakan untuk menggambarkan sistem secara umum/global dari keseluruhan sistem yang ada.

2. Data Flow Diagram (DFD)

Data Flow Diagram digunakan untuk menggambarkan suatu sistem yang telah ada atau sistem baru yang akan dikembangkan secara logika tanpa mempertimbangkan lingkungan fisik dimana data tersebut akan disimpan. Data flow diagram juga digunakan pada metodelogi pengembangan sistem yang terstruktur.

3. Entity Relationship Diagram (ERD)

Entity Relationship Diagram adalah sebuah pendekatan top-bottom dalam perancangan basis data yang dimulai dengan mengidentifikasikan data-data terpenting yang disebut dengan entitas, dan hubungan antara entitas-entitas tersebut yang digambarkan dalam suatu model.

\section{HASIL DAN PEMBAHASAN}

4.1 Analisa Sistem Yang Berjalan

Analisa sistem merupakan suatu tahap pemahaman proses yang bertujuan untuk mengetahui proses apa saja yang terlibat di dalam sistem, bagaimana kerja dari setiap proses yang terlibat didalam sistem dan hubungan suatu proses dengan proses yang lainnya. Dari pemahaman proses tersebut maka dapat dilakukan suatu evaluasi dan usulan terhadap sistem yang ada, untuk dikembangkan lebih lanjut.

\subsection{Evaluasi Sistem Yang Sedang Berjalan}

Evaluasi sistem pengelolahan data siswa, guru, dan karyawan di SMP Negeri 6 Prabumulih memang sudah menggunakan komputer dengan Aplikasi Microsoft Excel, dimana Microsoft Excel ini tidak dapat di akses pemakai secara bersamaan dan masih menggunakan flashdisk untuk saling tukar data dan informasi.

\subsection{Perancangan Sistem Yang di usulkan}

Tahap perancangan prosedur yang diusulkan ini akan dibuat diagram konteks, data flow diagram, tahap prosedur yang diusulkan ini merupakan pengembangan dari 
perancangan sistem yang diusulkan untuk menyelesaikan permasalahan.

\subsubsection{Diagram Konteks}

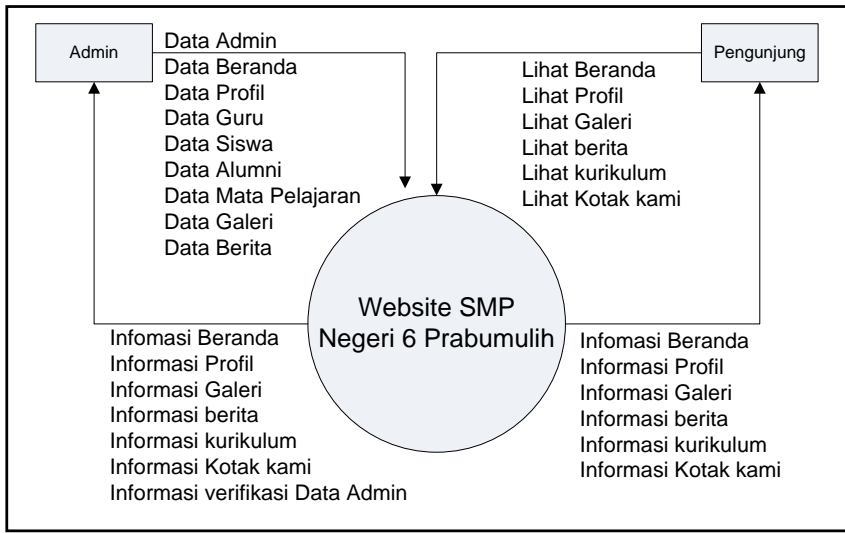

Gambar 4.1 Diagram Konteks

\subsubsection{Data Flow Diagram level 0}

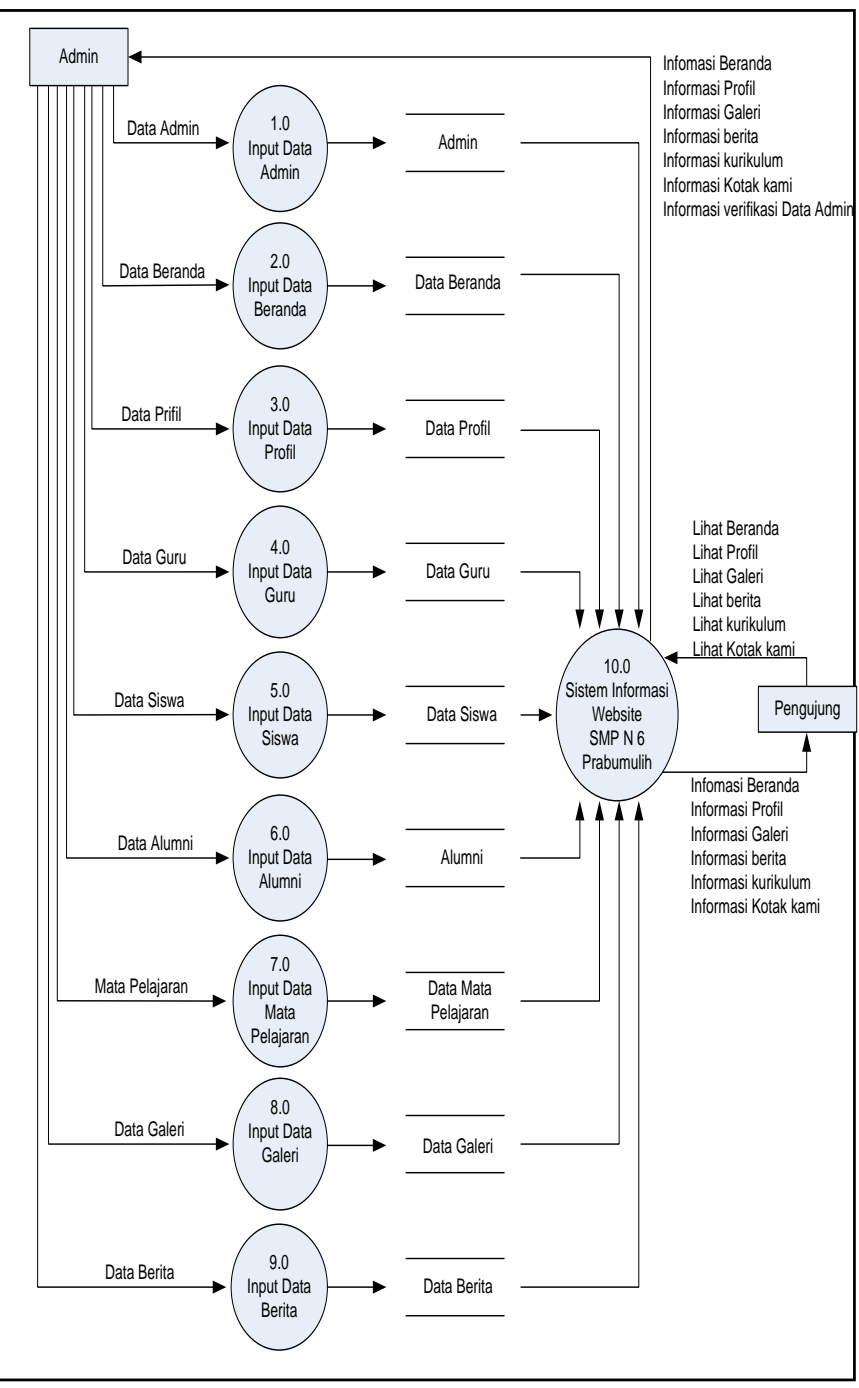

Gambar 4.2 Data Flow Diagram level 0

\subsubsection{Entity Relationship Diagram}

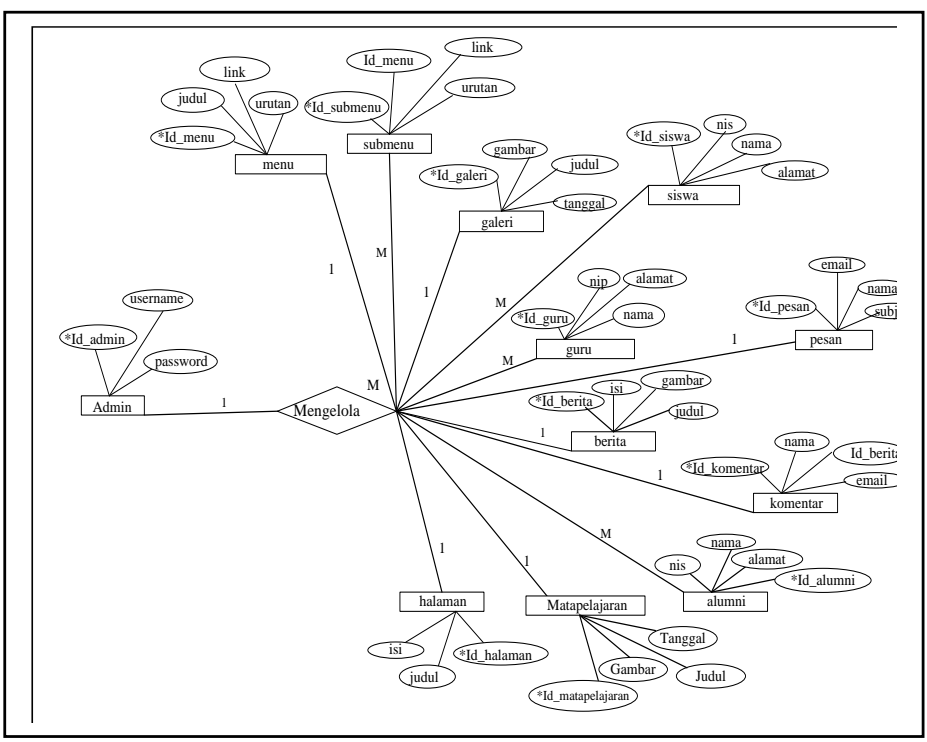

Gambar 4.3 Entity Relationship Diagram

\subsection{IMPLEMENTASI DAN PENGUJIAN SISTEM}

Tahap implementasi merupakan tahap penerapan sistem supaya dapat dioperasikan. Pada tahap ini dijelaskan mengenai, implementasi perangkat lunak, implementasi perangkat keras dan implementasi antar muka.

\subsection{Implementasi Perangkat Lunak}

Untuk mendukung sistem yang diusulkan bejalan dengan optimal dibutuhkan software pengolahan data, adapun perangkat lunak yang digunakan untuk mendukung pembuatan website sekolah ini sebagai berikut:

1. Sistem Operasi : Windows

2. Pembuatan Basis Data : Xampp Control Panel

Adapun perangkat keras yang digunakan untuk mendukung pembuatan website ini sebagai berikut:

Perangkat keras yang digunakan berdasarkan kebutuhan minimal yang harus terpenuhi adalah sebagai berikut:

1. Komputer/Laptop
a. Processor Intel Pentium Dual Core atau diatasnya
b. Harddisk $250 \mathrm{~GB}$ atau diatasnya
c. RAM $1 \mathrm{~GB}$
d. VGA $512 \mathrm{MB}$

\subsection{Pengujian Sistem}

Pada bagian pengujian sistem ini penulis menyajikan bahasan tentang apa yang akan kita temui pada website SMP Negeri 6 Prabumulih, menu dan langkah-langkah didalam pengoperasian dan serta proses menampilkan. Untuk menjalankan website SMP Negeri 6 Prabumulih dapat dilakukan sebagai berikut:

1. Nyalakan komputer/Laptop tunggu komputer/Laptop menampilkan area kerja.

2. Buka xampp klik start pada apache dan MySQl. 
3. Buka web browser mozila firefox atau google chorme

4. Dibagian addres bar ketik http://localhost/smpn6pbm/

5. Kemudian akan masuk kehalaman utama, masuk sebagai admin maka dibagian address bar ketik http://localhost/smpn6pbm/admin/

6. Kemudian akan masuk kehalaman login admin, masukkan username dan password.

4.7 Implementasi Antar Muka

1. Tampilan Halaman Login Admin

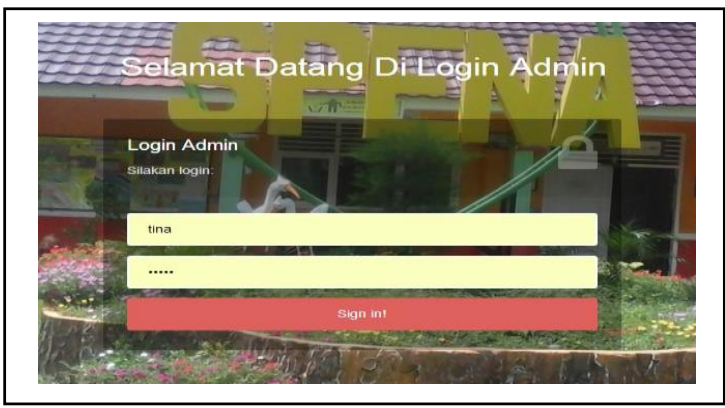

Gambar 4.4 tampilan Login Admin

2. Tampilan menu beranda pada website

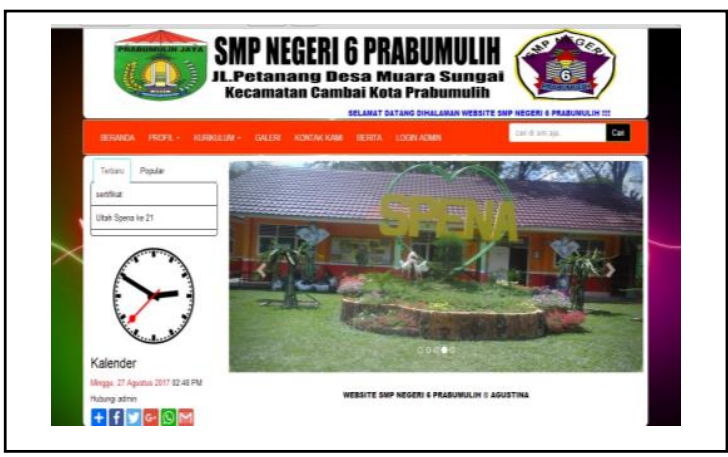

Gambar 4.5 tampilan beranda pada website

3. Tampilan visi dan misi pada website

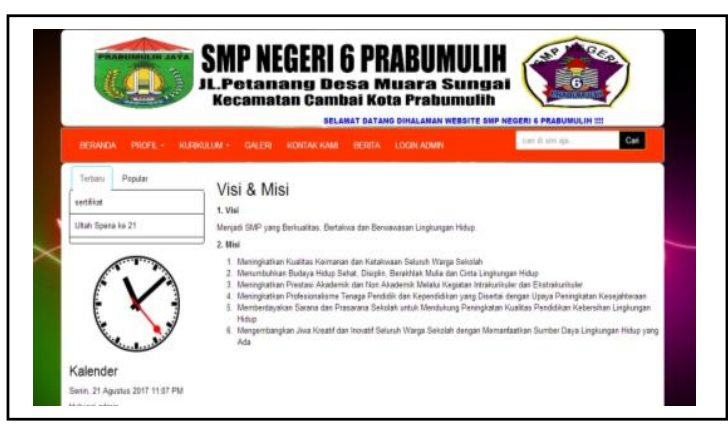

Gambar 4.6 Tampilan visi dan misi pada website
4. Tampilan sejarah pada website

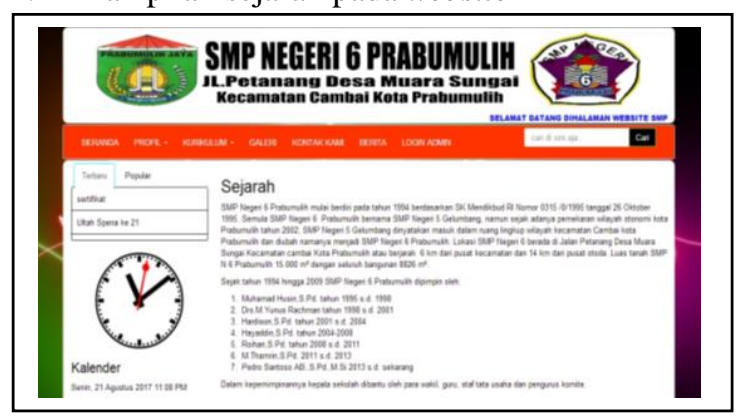

Gambar 4.7 Tampilan sejarah pada website

5. Tampilan kata sambutan pada website

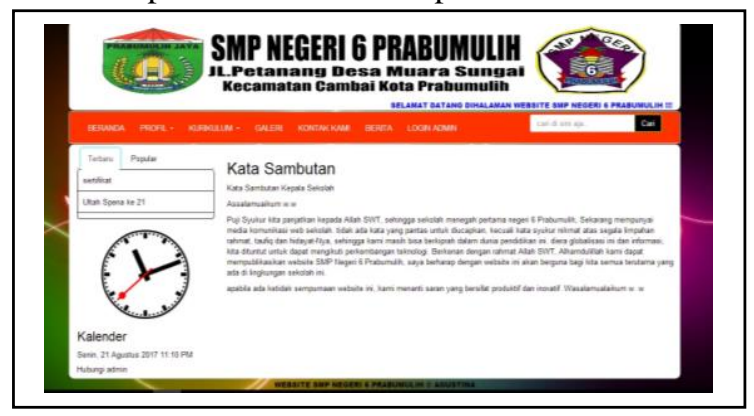

Gambar 4.8 Tampilan kata sambutan pada website

6. Tampilan data guru pada website

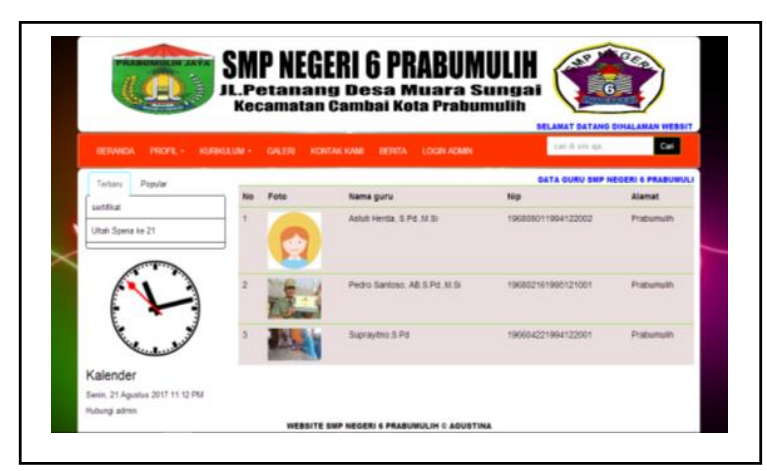

Gambar 4.9 Tampilan data guru pada website

7. Tampilan data siswa pada website

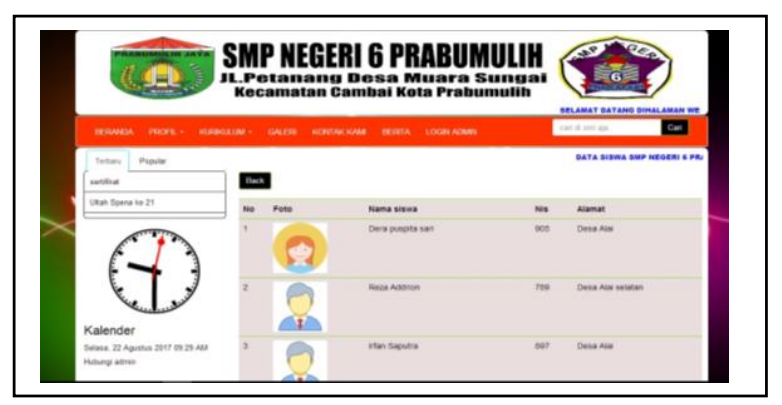

Gambar 4.10 Tampilan data siswa pada website 
8. Tampilan data alumni pada website

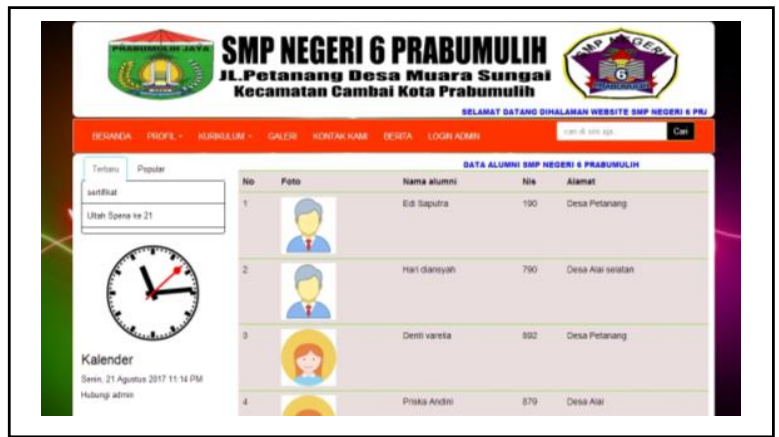

Gambar 4.11 Tampilan alumni pada website

9. Tampilan data mata pelajaran pada website

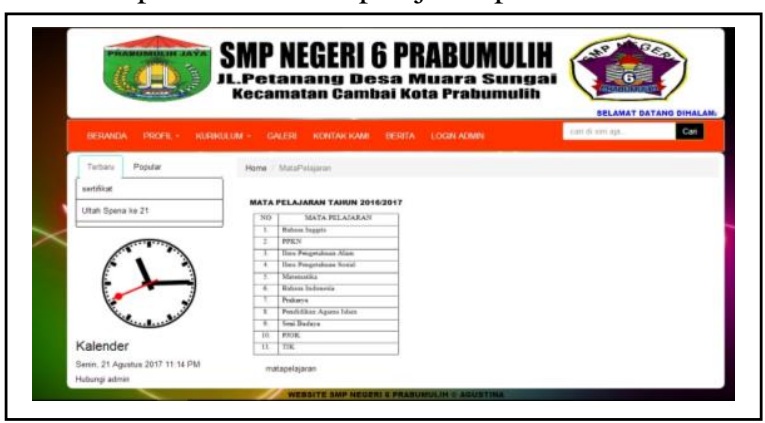

Gambar 4.12 Tampilan mata pelajaran pada website

10. Tampilan Menu galeri pada website

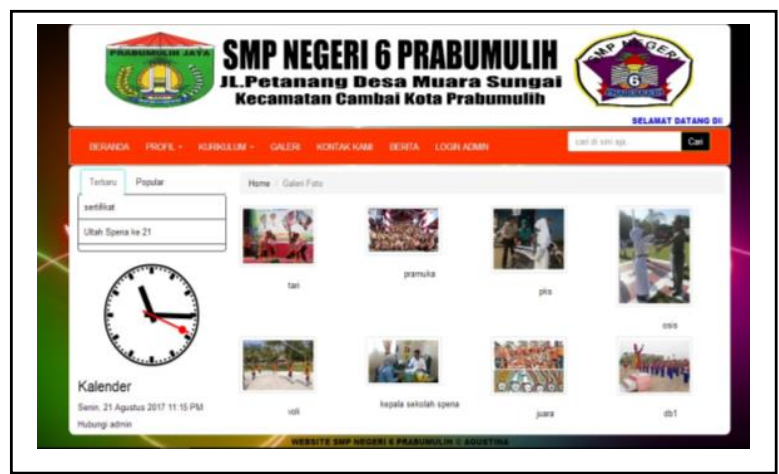

Gambar 4.13 Tampilan galeri pada website

11. Tampilan menu kontak kami website

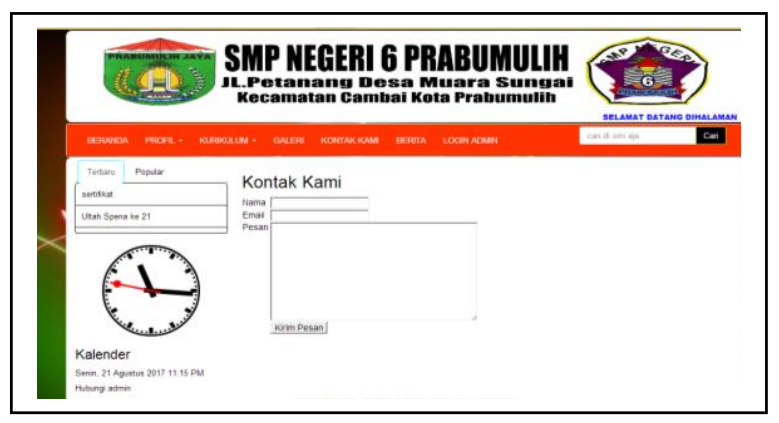

Gambar 4.14 Tampilan kontak kami pada website
12. Tampilan halaman website bootstrap

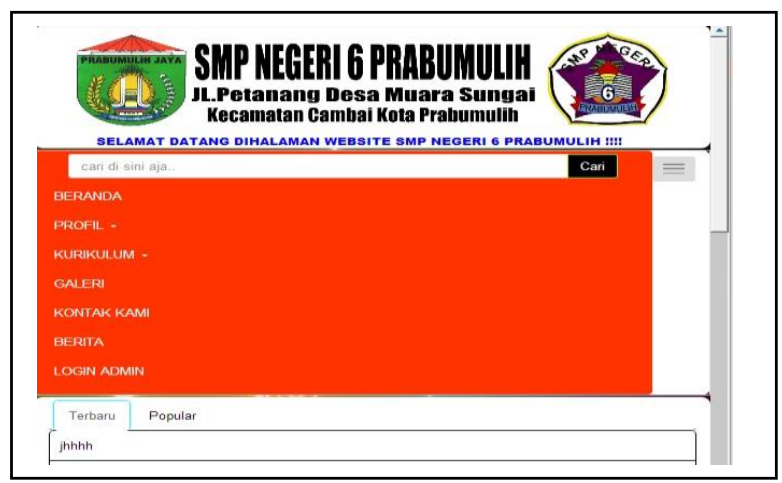

Gambar 4.15 Tampilan halaman website bootstrap

\section{PENUTUP}

5.1 Kesimpulan

1. Meningkatkan layana informasi tetang sekolah SMP Negeri 6 Prabumulih kepada masyarakat.

2. Mepermudah akses informasi bagi siswa,guru,kepala sekolah, dan masyarakat untuk mengetahui informasi sekolah.

3. Sistem informasi yang dibuat ini dapat mempermudah dalam melakukan proses pengolahan data informasi sekolah

4. Dengan adanya website ini diharapkan dapat membantu admin dalam pengontrolan data informasi.

\subsection{Saran}

1. Adanya pelatihan untuk admin tentang mengelola website, sehingga website Sekolah Menengah Pertama Negeri 6 Prabumulih ini berjalan dengan baik.

2. Sebaiknya Sekolah Menengah Pertama Negeri 6 Prabumulih menggunakan website ini, sehingga mempermudah untuk masyarakat mengetahui bagaimana informasi yang ada di Sekolah Menengah Pertama Negeri 6 Prabumulih.

3. Website ini masih memerlukan pemeliharaan dan analisisi terus menerus untuk mengetahui kekurangankekurangan yang mungkin tidak terpikirkan oleh penulis disaat proses pembuatannya dan perlunya pengembangkan sistem agar website ini lebih baik lagi dan bisa mengikuti sesuai perkembangan zaman dan kemajuan teknologi.

\section{DAFTAR PUSTAKA}

[1] Abdulloh, Rohi; 2016. "Web Programing is Easy \& Simple”, Jakarta: PT Elex Media Komputindo.

[2]. Jogiyanto, 2010. "Analisa dan desain sistem informasi", edisi IV.Yogjakarta: Andi Offset. 
[3] Nugroho,Bunafit; 2012. "Dasar pemrograman web PHPMySQL dengan Dreamweaver", Yograkarta: Gava media

[4] Raharjo, Budi; 2011. "Belajar Otodidak Pemrograman web dengan PHP + ORACLE", Bandung: Informatika.

[5] Rozi A. Zaenal \& Comunity Smit Dev, 2015. "Bootstrap Design Framework", Jakarta: PT Elex Media Komputindo.
[6] Sadeli, Muhammad, 2014. "Aplikasi Bisnis dengan PHP \& MySQL menggunakan Adobe Dreamweaver CS 6", Palembang: Maxikom.

[7] Sadeli, Muhammad, 2011. "Dreamweaver CS5 untuk orang awam", Palembang: Maxikom.

[8] Usep Teisnajaya, 2015. "Rancang Bangun Aplikasi Penjualan Dan Pemasaran Barang Pada Cabang Pemasaran Perseroan Terbatas (PT) Halim Jaya Sakti Palembang”, Jurnal Informatika, Vol 1 januari- juni 201 